\title{
Evaluation of a Novel Semi-Automated Ultrasound System for the Detection of Synovitis: A Prospective Study involving 45 Patients with Rheumatoid Arthritis
}

\author{
Authors \\ M. Witt ${ }^{1}$, J. Frielinghausen ${ }^{1}$, R. Mueller ${ }^{2}$, F. Mueller ${ }^{1}$, F. Proft ${ }^{1}$, H. Schulze-Koops ${ }^{1}$, M. Grunke ${ }^{1}$, \\ D.-A. Clevert ${ }^{3}$ \\ Affiliations \\ Affiliation addresses are listed at the end of the article
}

\section{Key words \\ ultrasound \\ - arthritides \\ - technical aspects \\ fingers and toes}

received 17.04.2016

accepted $\quad 04.08 .2016$

Bibliography

DOI http://dx.doi.org/

10.1055/s-0042-115774

Published online:

September 14, 2016

Ultrasound International Open

2016; 2: E117-E123

(c) Georg Thieme Verlag KG

Stuttgart · New York

ISSN 2199-7152

\section{Correspondence}

\section{Dr. Matthias Witt}

Division of Rheumatology

Med. Klinik und Poliklinik IV

Pettenkoferstraße 8a

80336 Munich

Germany

Tel.: + 49/89/440053579

matthias.witt@

med.uni-muenchen.de

\section{Abstract}

$\nabla$

Background: Arthrosonography has proven to be more sensitive and reliable for the detection of synovitis than clinical examination, but a comprehensive examination of small joints is time-consuming. The automated breast volume scanner (ABVS) has been developed to allow automatic and reproducible series of consecutive B-mode pictures of the female breast.

Objectives: To analyze the comparability of ABVS and conventional manual ultrasonography (mUS) for the detection of synovitis in hands and feet of patients with rheumatoid arthritis (RA). Methods: 45 patients with early and established active rheumatoid arthritis were recruited for this trial. All subjects were assessed clinically and by manual (Esaote MyLab70) and automated ultrasound (ACUSON S2000 ${ }^{\mathrm{TM}}$ ABVS). The wrists, the metacarpophalangeal and proximal inter-

\section{Background}

The reliable detection of synovitis is critical for diagnosing and assessing disease activity in rheumatoid arthritis. The confirmation of synovitis is the main feature not only of classification criteria for rheumatoid arthritis and other polyarthritic diseases [1-3], but also of composite scores of disease activity [4-6]. The absence of synovitis is the precondition for the definition of disease remission, our main therapeutic target $[7,8]$. As the goal is to classify and treat the disease as early as possible, highly sensitive detection of articular abnormalities is essential. In daily practice, however, reliable detection of synovitis can pose substantial difficulties for the treating physician [9]. Physical examination, which has been the main diagnostic tool for decades, yields significantly different results between examiners $[10,11]$. Even with standard- phalangeal joints of the hands and the metatarsophalangeal joints of the feet were examined. Results: A total of 2340 joint aspects were examined with both methods. ABVS detected 291 grade 1, 124 grade 2, 100 grade 3 cases of synovitis (515 in total) compared to 267, 180 and 145 cases of synovitis (592 in total) with mUS. 242 erosions and 52 cases of tenosynovitis were found by ABVS compared to 244 erosions and 99 cases of tenosynovitis found by mUS. Kappa coefficients for the agreement between both methods ranged from 0.51 in PIP joints to 0.71 in MCP joints. The correlations with clinical parameters as well as interrater agreements were comparable for both ultrasound methods.

Conclusion: Based on the results, ABVS seems to be a promising technology for the comprehensive and time-saving assessment of synovitis in RA.

ized training programs, these differences can be improved but not eliminated with kappa values for physical examination between 0.2 and 0.6 depending on the joint region examined $[12,13]$. Additionally, physical examination techniques seem to be insensitive compared to modern diagnostic tools.

In recent years, high-resolution ultrasound has proven to be a very sensitive method for the detection of even small amounts of synovitis [14]. In this respect it is clearly superior to manual examination $[15,16]$. Moreover, with the addition of the Doppler technique, inflammatory hyperperfusion of the synovium can be visualized. Even bony erosions can be traced much earlier than by employing conventional radiography $[17,18]$. The disadvantages of arthrosonography are its dependency on the level of expertise of the examiner, the difficulty of standardization and reproducibility and the amount of time 
needed for a comprehensive examination [19,20]. Magnetic resonance imaging (MRI) has a comparable sensitivity to ultrasound for detecting synovitis and bony erosions [21,22]. Inflammation can be illustrated using the appropriate sequences and contrast media. The reproducibility is better than with ultrasound, but a skilled examiner is again needed for the interpretation of results [23]. Moreover, this technique is expensive and usually only one extremity can be captured during one diagnostic session.

The "automated breast volume scanner" (ABVS, ACUSON S2000TM ABVS; Siemens Medical Solutions, Inc., Mountain View, CA) has recently been developed for the acquisition of series of consecutive B-mode pictures of the female breast $[24,25]$. These pictures can be analyzed in all 3 dimensions and reconstructed to $3 \mathrm{D}$ data sets. The ABVS can be operated by an assistant medical technician and the acquired data can be sent to a separate workstation to be independently analyzed by a specialist. Similar to conventional ultrasound, ABVS has shown a high sensitivity in the detection of breast abnormalities and excellent prediction of lesion size [26-28]. Even the differentiation between benign and malignant lesions was comparable between ABVS and manual ultrasound [29]. In patients suspected for breast tumors, the detection rate was even higher compared to manual ultrasound [30].

In a recent trial, we tested the transferability of ABVS to the wrists and finger joints of patients with rheumatoid and psoriatic arthritis [31]. A similar trial has recently been published by Kawashiri et al. [32], which evaluated ABVS and manual ultrasound in 14 patients with rheumatoid arthritis. The present study was conducted to confirm the comparability of this new development with manual ultrasound (mUS) in a large cohort of patients with active early and established rheumatoid arthritis and to extend it to the assessment of tenosynovitis in the hands and synovitis in the small joints of the feet.

\section{Patients and Methods}

$\nabla$

A total of 45 patients with either established or newly diagnosed RA were recruited into this study. Diagnosis of RA was based on the modified ACR criteria of 1987 [2] or the ACR/EULAR criteria of 2010 [1]. Newly diagnosed RA was defined as a disease duration of less than 2 years and no pretreatment with disease-modifying antirheumatic drugs. All patients gave written informed consent for participation in the trial, which was approved by the Ethics Committee of the University of Munich. All individuals were clinically assessed with a 66/68-joint count according to the EULAR technique and a DAS28 and were asked to fill out the health assessment questionnaire (HAQ).

All patients then underwent conventional ultrasound (manual ultrasound, mUS) examination of the wrists, metacarpophalangeal (MCP), proximal interphalangeal (PIP) and metatarsophalangeal (MTP) joints. MCP and PIP joints were assessed from the palmar and dorsal aspect. B-mode findings consistent with synovitis were graded semiquantitatively as previously specified. Briefly, grade one was defined as a small anechoic line beneath the joint capsule, grade 2 as capsule distension parallel to the joint area, and grade 3 as pronounced convex distension of the joint capsule $[19,33,34]$. Flexor tendons of the $1^{\text {st }}$ through $5^{\text {th }}$ digit of both hands were assessed on the wrist and finger level for the presence of tenosynovitis. B-mode findings consistent with tenosynovitis were graded on a binary scale and were defined as abnormal anechoic or hypoechoic widening of the tendon sheath related to the presence of tenosynovial fluid [35]. Finally, erosions were defined as a clear cortical break of at least $2 \mathrm{~mm}$ with a basal reflex seen in 2 planes with mUS or on at least 2 consecutive layers with ABVS. Dorsal carpal, distal metacarpal and proximal and distal interphalangeal bone areas were searched for erosions [36]. Ultrasound assessments were performed on a high-resolution ultrasound system (MyLab70 ${ }^{\odot}$, Esaote, Italy) with an $8-18 \mathrm{MHz}$ probe for the assessment of small joints and a $5-13 \mathrm{MHz}$ probe for the assessment of the wrists. Automated ultrasound was conducted on the same day as conventional ultrasound using the ACUSON S2000 ${ }^{\mathrm{TM}}$ ABVS (Siemens Medical Solutions, Mountain View, USA). The ABVS transducer was equipped with a linear array (5-14 MHz bandwidth). The frequency was set to $11 \mathrm{MHz}$, and each ABVS examination was performed with a longitudinal radial-to-ulnar automatic sweep of the scanner which generated $15.4 \times$ $16.8 \mathrm{~cm} \times 2.5 \mathrm{~cm}$ volume data sets. The system was set to provide an automatic scanning time of $65 \mathrm{~s}$ per scan with a slice thickness of $0.5 \mathrm{~mm}$. The dorsal and palmar sides of each hand and the dorsal aspect of the toes were scanned separately. Data were saved and transferred from the ABVS to the ACUSON S2000 ${ }^{\mathrm{TM}}$ ABVS workstation. Multiplanar reconstruction enabled examination of the images at multiple levels for the presence of bony lesions or joint swelling. To reduce artifacts from air entrapment, the hands and feet of the study subjects were positioned in a water basin and the ultrasound probe was positioned directly beneath the surface of the water ( $\bullet$ Fig. 1 and $\bullet$ Fig. 2). mUS examinations were performed by a physician. ABVS examinations were performed by a technician and read-out by a physician.

Cohen's kappa coefficients for the assessment of interrater, intrarater and intermethod agreement were calculated and based on methods previously described. The following cut-off values for agreement were defined: $<0.0=$ none, $0-0.20=$ poor, $0.21-$ 0.40: modest, $0.41-0.60=$ fair, $0.61-0.80=$ good, $0.81-$ $1.00=$ excellent. Correlations were assessed by Pearson's correlation analysis. For the correlations of ABVS and mUS, sum scores of the semiquantitative ultrasound findings of ABVS and mUS were calculated for each patient and correlated with each other and the respective clinical parameters of disease activity. The ABVS and mUS sum scores were calculated by adding up the semiquantitative ultrasound findings of the examined joints of a patient and theoretically could range between 0 and 96 per patient (10 MCP, 10 PIP, 10 MTP and 2 wrist joints per patient with grade 0 to 3 per joint). Significant changes were calculated by Fisher's tests. P-values of less than 0.05 were considered statistically significant. The statistical analysis was calculated with SPSS software, version 20.0 (IBM, Armonk, NY), and with Prism 5 software, version 5.2 (Prism, LaJolla, CA). This study was part of the "ArthroMark" network, which is funded by the German Federal Ministry of Education and Research.

\section{Results \\ $\nabla$}

\section{Baseline characteristics of the study population}

A total of 45 patients were included in the study. $80 \%$ of the patients were female. The mean age was $58.9 \pm 13.2$ years. 17 patients $(37.8 \%$ ) had a new diagnosis of therapy-naïve rheumatoid arthritis, while the rest of the patients had the diagnosis of established disease. 31 patients (68.9\%) and 25 patients (55.6\%) 

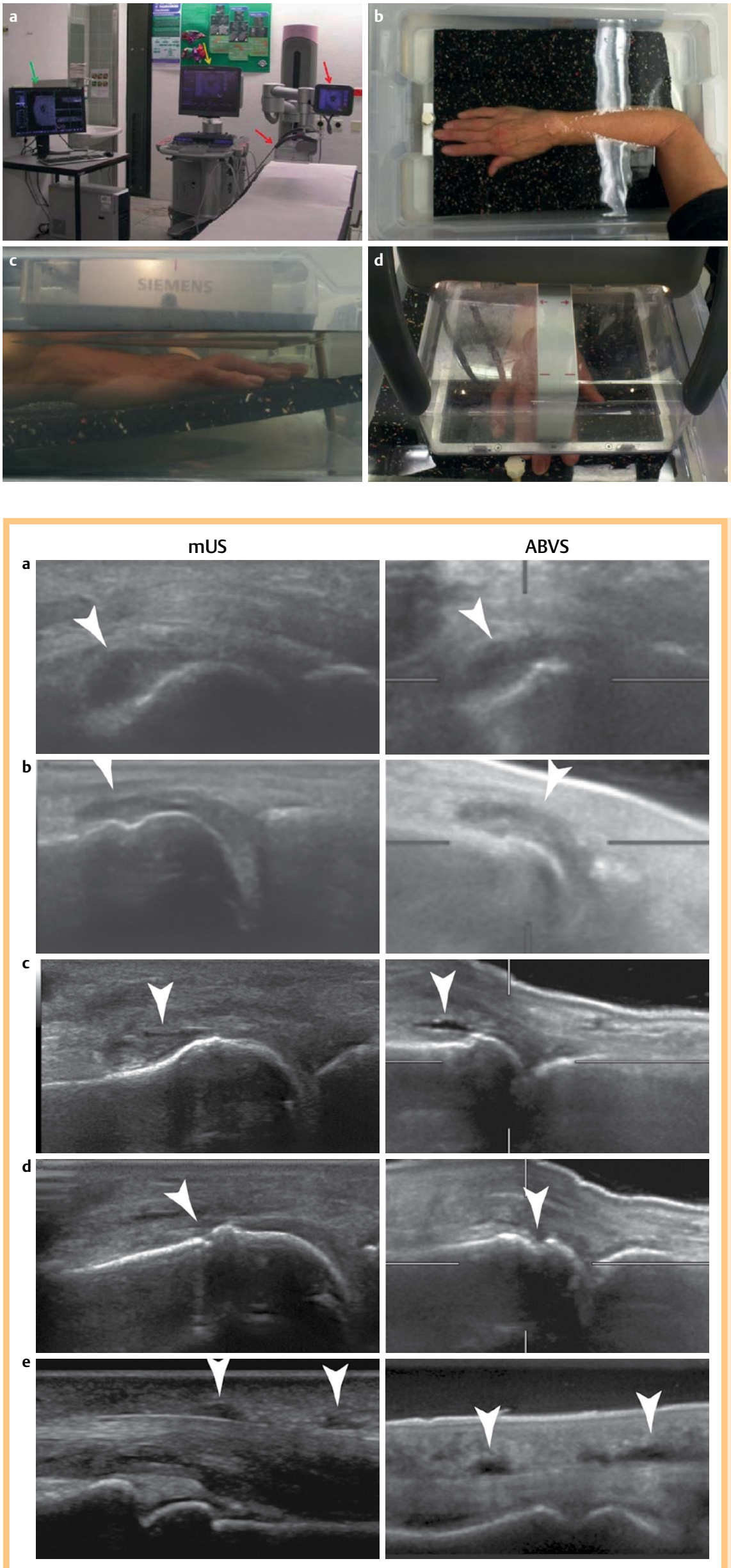
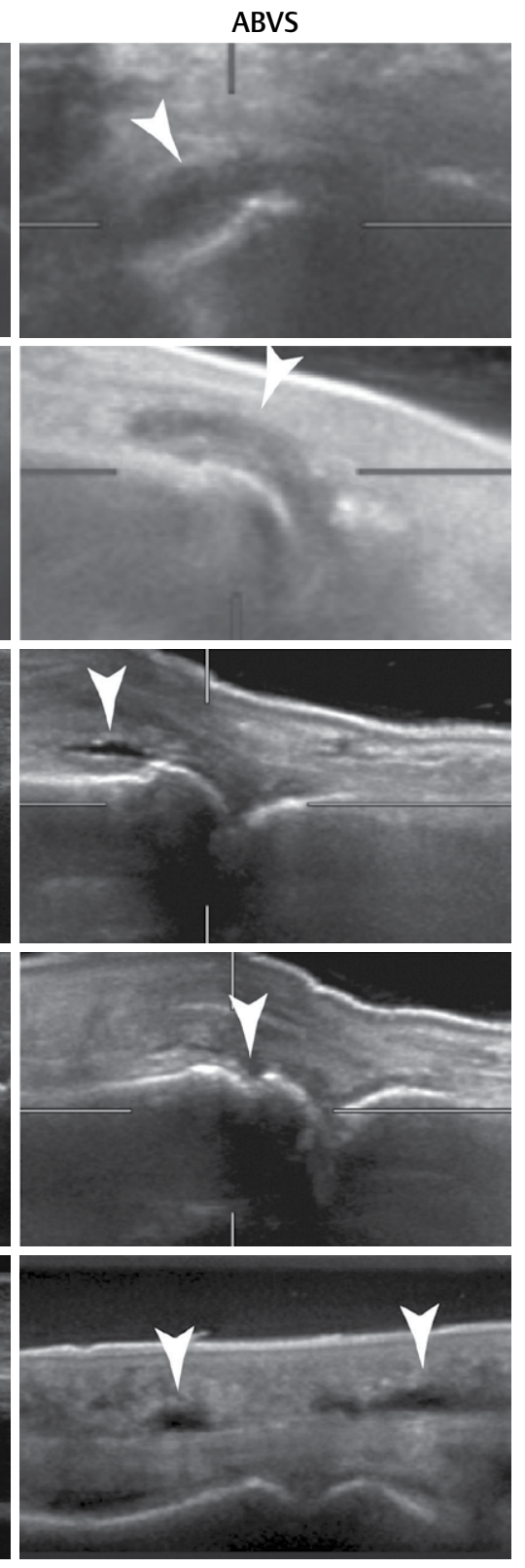

Fig. 1 a the ABVS system with the adjustable scanner, ultrasound machine and work station (arrows). b Positioning of a patient's hand in temperate water. (c and d) Positioning of the automated scanner above the patient's hand. Of note, the probe does not make contact with the skin, thereby avoiding compression artifacts.
Fig. 2 Representative corresponding images of synovitis, erosions and tenosynovitis (arrows) detected by mUS and ABVS. mUS and ABVS images were acquired with $18 \mathrm{MHz}$ and $11 \mathrm{MHz}$ probes, respectively. a MCP 3 joint with grade 2 synovitis. b MTP 2 joint with grade 2 synovitis. c MCP 3 joint with grade 1 synovitis. d MCP 3 joint with erosions. e Index finger tenosynovitis of the flexor tendon. 
Table 1 Baseline characteristics of the study population.

\begin{tabular}{ll}
\hline Patients total/early/established $(\mathrm{n})$ & $45 / 17 / 28$ \\
\hline Age (mean with SD) & $58.9 \pm 13.2$ years \\
Female: male ( $\mathrm{n})$ & $36: 9$ \\
\hline RF positive/ACPA positive (\%) & $68.8 / 55.5$ \\
\hline Tender joints of 28-joint count (mean with SD) & $6.3 \pm 6.4$ \\
Swollen joints of 28-joint count (mean with SD) & $6.6 \pm 5.3$ \\
DAS-28 (mean with SD) & $4.1 \pm 1.7$ \\
CDAl (mean with SD) & $21.2 \pm 14.1$ \\
SDAl (mean with SD) & $22.5 \pm 15.3$ \\
HAQ (mean with SD) & $1.1 \pm 0.7$
\end{tabular}

were positive for rheumatoid factor and anti-citrullinated peptide antibodies (ACPA), respectively. Mean disease activity as assessed by DAS-28, CDAI and SDAI was $4.1 \pm 1.7,21.2 \pm 14.1$ and $22.5 \pm 15.3$, respectively ( $\bullet$ Table 1 ).

Time expenditure of mUS and ABVS assessments The complete assessment of wrists, fingers and toes by manual ultrasound including documentation of the results took about 15 min for the examining physician. ABVS examination including preparation of the water basin, positioning of the patient and acquisition of the images took about $10 \mathrm{~min}$ for a medical assistant. Thorough evaluation of the data set took about $3 \mathrm{~min}$ for a physician.

\section{Interrater and intrarater evaluation of mUS and ABVS}

For the evaluation of intrarater and interrater reliabilities, ABVS images of 450 randomly selected joints were independently assessed by MW and MG. The interrater kappa values for the detection of synovitis, erosions and tenosynovitis with ABVS were $0.78,0.77$ and 0.83 , respectively. The mean intrarater kappas for the detection of synovitis, erosions and tenosynovitis were $0.59,0.72$ and 0.84 , respectively ( $\bullet$ Table 2 ).

\section{mUS and ABVS examined and evaluable joints}

A total of 2340 joint aspects were examined by mUS and ABVS each: 450 MCP joints, 450 PIP joints, 90 wrist joints and 450 MTP joints. The MCP and PIP joints were examined from the dorsal and palmar aspect. 80 (3.4\%) joints were judged not evaluable by mUS, compared to $414(17.6 \%)$ non-evaluable joints by ABVS ( $<<0.001)$. Comparing dorsal and palmar ABVS examinations, 103 (11.1\%) MCP and PIP joints were not evaluable from the dorsal aspect, compared to 300 (33.3\%) non-evaluable MCP and PIP joints from the palmar aspect $(\mathrm{p}<0.001)$. Most non-evaluable joints were detected in the MTP region for both methods with $62(13.8 \%)$ joints for mUS and 103 (22.9\%) joints for ABVS.

\section{Detection of synovitis with mUS and ABVS}

With mUS, 217 (48.2\%), 179 (39.8\%), 49 (54.4\%) and $149(33.1 \%)$ synovitic findings were detected in MCP, PIP, wrist and MTP joints, respectively, compared to 229 (50.9\%), 121 (26.9\%), 34 (37.8\%) and 131 (29.1\%) synovitic findings detected in MCP, PIP, wrist and MTP joints by ABVS. The differences between mUS and ABVS were significant for PIP and wrist joints ( $\bullet$ Fig. 3 ). ABVS detected 291 grade 1,124 grade 2,100 grade 3 cases of synovitis (515 in total) compared to 267, 180 and 145 case of synovitis (592 in total) with mUS. The kappa coefficients for the detection of synovitis were $0.71,0.51,0.69$ and 0.53 for dorsal MCP, dorsal PIP, wrist and MTP joints, respectively. The kappa coefficients after the exclusion of grade 1 synovitic findings increased to 0.73
Table 2 Overview of Cohen's kappa agreements of intra- and interrater and intermethod assessments.

\begin{tabular}{|c|c|}
\hline & Cohen's kappa \\
\hline \multicolumn{2}{|c|}{ Intrarater agreement ABVS * } \\
\hline Synovitis & 0.59 \\
\hline Erosions & 0.72 \\
\hline Tenosynovitis & 0.84 \\
\hline \multicolumn{2}{|c|}{ Interrater agreement ABVS } \\
\hline Synovitis & 0.78 \\
\hline Erosions & 0.77 \\
\hline Tenosynovitis & 0.83 \\
\hline \multicolumn{2}{|c|}{ Intermethod agreement (mUS vs. ABVS) } \\
\hline \multicolumn{2}{|l|}{ Synovitis } \\
\hline MCP & 0.71 \\
\hline PIP & 0.51 \\
\hline wrist & 0.69 \\
\hline MTP & 0.53 \\
\hline \multicolumn{2}{|l|}{ Erosions } \\
\hline MCP & 0.59 \\
\hline PIP & 0.55 \\
\hline wrist & 0.21 \\
\hline MTP & 0.38 \\
\hline \multicolumn{2}{|l|}{ Tenosynovitis } \\
\hline Finger flexor tendons & 0.61 \\
\hline
\end{tabular}

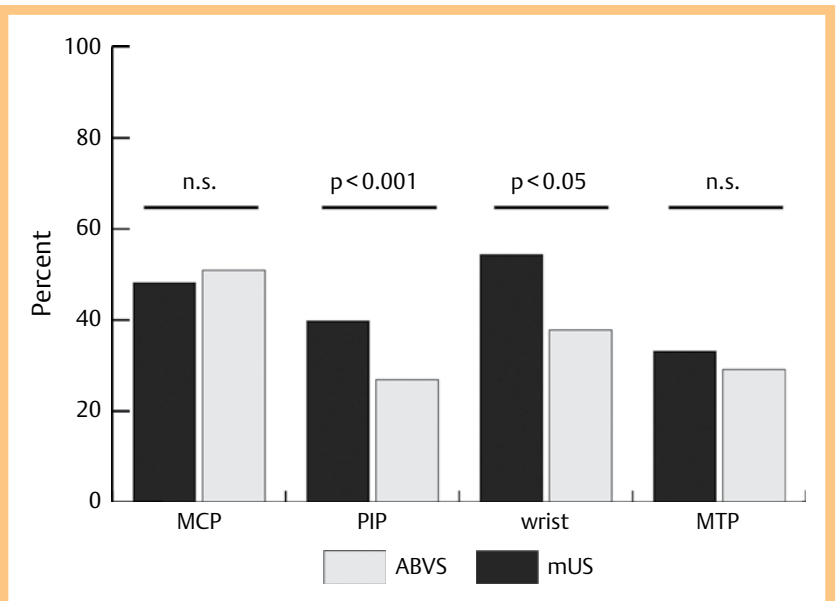

Fig. 3 Examined joint regions with the percentages of positive findings identified by ABVS and mUS (n. s. $=$ not significant).

for MCP joints, but not for PIP, wrist and MTP joints. In general, ABVS showed a tendency for rating lower grades than mUS in the same joint ( $\bullet$ Table 2 ).

\section{Detection of flexor tendon tenosynovitis with mUS and ABVS}

450 flexor tendons were evaluated by mUS and ABVS on the wrist and finger level. While 6 tendons were judged non-evaluable with mUS, 162 were not evaluable by ABVS (36.0\%). In the evaluable tendons, ABVS detected 31 and 21 findings consistent with flexor tendon tenosynovitis on the MCP and/or PIP level, compared to 72 and 27 findings of flexor tendon tenosynovitis on the MCP and/or PIP level with mUS. Comparing mUS with 

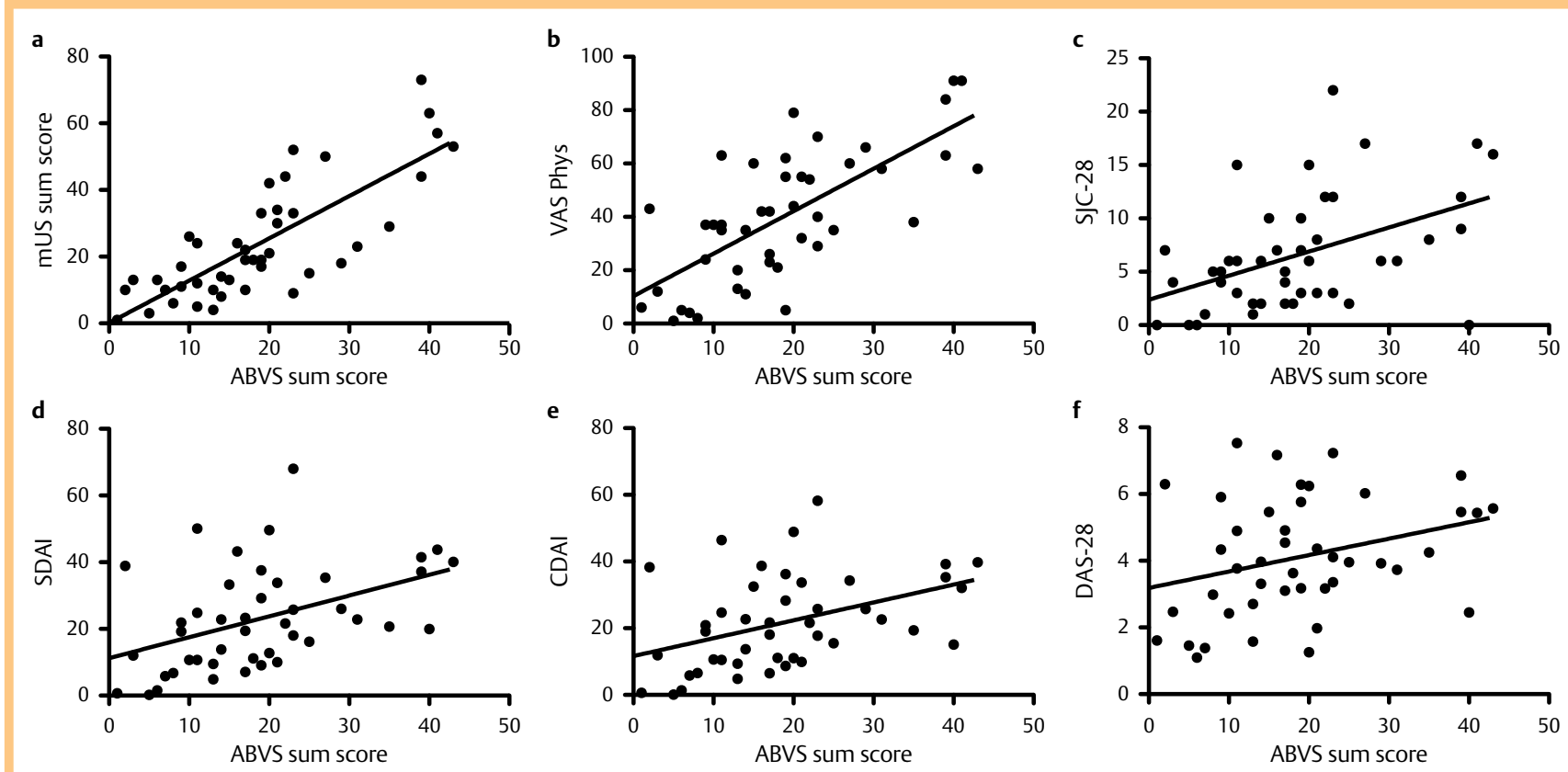

Fig. 4 Pearson's correlations of the patients' ABVS sum scores with the respective a mUS sum scores and clinical parameters of disease activity, $\mathbf{b}$ physician's VAS, c 28-joints swollen joint count, $\mathbf{d}$ simplified disease activity index, e clinical disease activity index and $\mathbf{f}$ DAS-28 (see methods for details of the mUS and ABVS sum scores).

corresponding evaluable ABVS flexor tendons, the kappa coefficient for the detection of flexor tendon tenosynovitis was 0.61 (० Table 2).

\section{Detection of erosions with mUS and ABVS}

mUS detected 120, 62, 51 and 11 erosions of MCP, PIP, MTP and wrist joints, respectively, compared to 106, 74, 24 and 38 erosions detected with ABVS. The kappa coefficients for the detection of erosions were $0.59,0.55,0.38$ and 0.21 for MCP, PIP, MTP and wrist joints, respectively.

\section{Correlation of ABVS with mUS and clinical parameters}

For the correlation of ABVS with mUS and clinical parameters, semiquantitative sum scores of ABVS and mUS findings of the patients were calculated and correlated. The correlation of ABVS with mUS was 0.79 . The correlation of ABVS with the physician's VAS was 0.71. Fair correlations of ABVS were found with 0.46 , 0.45 and 0.41 for the swollen joint count, SDAI and CDAI, respectively. Correlations with the assessed clinical parameters were comparable for mUS and ABVS sum scores ( $\bullet$ Fig. 4).

\section{Discussion}

\section{$\nabla$}

The trial population consisted of patients with newly diagnosed, therapy-naive and established rheumatoid arthritis. On average, the population had moderate to severe disease activity as documented by DAS-28, CDAI and SDAI and therefore seemed suitable for the evaluation of a new ultrasound technique. For the comparison of the performances of ABVS and mUS, we assessed several statistical parameters such as the intra- and interrater agreements of ABVS, the correlation of ABVS with mUS and with clinical parameters and, finally, the agreements of both methods with each other. We chose, not to define a gold standard since both methods use the same ultrasound technique just with different application methods and also have their specific advantages and disadvantages. For example, mUS offers more dynamic examination in the hands of an experienced sonographer, while ABVS allows a standardized image acquisition approach with less dependence on the assessor. As others did before us in similar settings, we therefore thought of Cohen's kappa coefficients as an appropriate statistical tool to investigate the agreement between automated and manual ultrasound examination [32].

The inter- and intrarater agreements of ABVS were similar to those seen for mUS in our own observations and in the literature $[14,37,38]$. The overall ability to detect synovitis, erosions and tenosynovitis was comparable for both methods, although ABVS was less sensitive in the wrists and MTP joints. The lack of a dynamic examination with ABVS may be a reason for this lower sensitivity. Related to this, kappa agreements between ABVS and mUS also depended on the joint region examined. They were good in the MCP and fair in the wrist, PIP and MTP joints. Excluding grade 1 findings, as suggested for the assessment of finger joints by several investigators $[14,32]$, led to an overall kappa improvement of MCP joints. Based on this data, we would estimate that the ABVS examination of the dorsal aspect of MCP and PIP joints is more reliable and comparable to mUS than the palmar aspect. The overall correlation of ABVS with mUS was good. Further, ABVS findings correlated well with the physician's estimation of disease activity and fairly with other parameters such as the DAS-28, CDAI and SDAI. All correlations found for ABVS were comparable to those found for mUS in this study and to those reported previously [33,39].

The ABVS ultrasound method has some noteworthy limitations. First, we faced a comparably high percentage of non-evaluable MCP and PIP joints from the palmar aspect as well as a high percentage of non-evaluable MTP joints. The former resulted from the fact that many patients had difficulties positioning their 
hand in the required maximum supination. The latter was a problem in patients with established RA, in which the proportion of advanced deformities of the MTP joints is higher than in newly diagnosed patients. Together with the better kappa agreements between mUS and ABVS for MCP and PIP joints from the dorsal aspect, this argues for dorsal acquisition as the appropriate approach. This is also in line with our own observations for mUS, which favor the assessment of the dorsal aspect of MCP and PIP joints [40]. Second, ABVS is currently not equipped with power Doppler, which is of considerable importance for diagnostic and prognostic information in active as well as in inactive RA [41-43]. Finally, the ABVS probe was limited to a frequency of $11 \mathrm{MHz}$, while in current ultrasound examinations of small joints, probes with up to $18 \mathrm{MHz}$ are commonly applied for the purpose of better resolution. Future improvements of the technical setup may help to minimize these limitations.

Thorough ultrasound examination of the joints is time-consuming. Recently, ultrasound scores that focus on certain index joints have been proposed to account for this [33,44-46]. There is a delicate balance between comprehensive assessment and time constraints. In light of this, semi-automatization of imaging is an issue in rheumatology. The goal is quick and reproducible acquisition of images without cost-intensive personnel costs. In our study, data sets were acquired and processed quicker with ABVS than with conventional mUS and if considering image read-out only, the time-saving advantages were evident. To date, some approaches to this issue have been provided by techniques like the Xiralite Rheumascan ${ }^{\circledR}$ or optical spectral transmission techniques $[47,48]$. MRI is one of the established methods. While all these approaches have certain advantages and disadvantages, the advantages of ABVS include the lack of application of an injectable contrast agent and good resolution of the anatomical structures.

In conclusion, ABVS showed good ability regarding the detection of synovitis, tenosynovitis and erosions. Furthermore, acceptable agreement with mUS was achieved in joint regions relevant in rheumatoid arthritis like the MCP joints. Together with the advantage of quick acquirement of images without the need of a physician, ABVS may be an interesting tool for the detection of synovitis and further evaluation in larger cohorts seems warranted.

\section{Acknowledgements}

$\nabla$

M. Grunke and D.-A. Clevert contributed equally to this work.

\section{Affiliations}

Division of Rheumatology, Med. Klinik und Poliklinik IV, University of

Munich, Munich, Germany

Division of Rheumatology, Kantonsspital St. Gallen, St. Gallen, Switzerland

${ }^{3}$ Department of Clinical Radiology, University of Munich, Munich, Germany

\section{References}

1 Aletaha D, Neogi T, Silman AJ et al. 2000 Rheumatoid arthritis classification criteria: an American College of Rheumatology/European League Against Rheumatism collaborative initiative. Arthritis Rheum 2010; 62: 2569-2581

2 Arnett FC, Edworthy SM, Bloch DA et al. The American Rheumatism Association 1987 revised criteria for the classification of rheumatoid arthritis. Arthritis Rheum 1988; 31: 315-324

3 Taylor W, Gladman D, Helliwell $P$ et al. Classification criteria for psoriatic arthritis: development of new criteria from a large international study. Arthritis Rheum 2006; 54: 2665-2673
4 van der Heijde DM, van't Hof M, van Riel PL et al. Validity of single variables and indices to measure disease activity in rheumatoid arthritis. J Rheumatol 1993; 20: 538-541

5 Felson DT, Anderson JJ, Boers $M$ et al. The American College of Rheumatology preliminary core set of disease activity measures for rheumatoid arthritis clinical trials. The Committee on Outcome Measures in Rheumatoid Arthritis Clinical Trials. Arthritis Rheum 1993; 36: 729-740

6 Aletaha D, Smolen JS. The simplified disease activity index and clinical disease activity index to monitor patients in standard clinical care. Rheum Dis Clin North Am 2009; 35: 759-772

7 Smolen JS, Aletaha D, Bijlsma JW et al. Treating rheumatoid arthritis to target: recommendations of an international task force. Ann Rheum Dis 2010; 69: 631-637

8 Keystone EC, Smolen J, van Riel P. Developing an effective treatment algorithm for rheumatoid arthritis. Rheumatology (Oxford) 2012; 51 (Suppl 5): 48-54

9 Scott DL, Antoni C, Choy EH et al. Joint counts in routine practice. Rheumatology (Oxford) 2003; 42: 919-923

10 Grunke $M$, Witt MN, Ronneberger $M$ et al. Use of the 28-joint count yields significantly higher concordance between different examiners than the 66/68-joint count. J Rheumatol 2012; 39: 1334-1340

11 Sokka T, Pincus $T$. Joint counts to assess rheumatoid arthritis for clinical research and usual clinical care: advantages and limitations. Rheum Dis Clin North Am 2009; 35: 713-722

12 Grunke M, Antoni CE, Kavanaugh A et al. Standardization of joint examination technique leads to a significant decrease in variability among different examiners. J Rheumatol 2010; 37: 860-864

13 Scott DL, Choy EH, Greeves A et al. Standardising joint assessment in rheumatoid arthritis. Clin Rheumatol 1996; 15: 579-582

14 Witt M, Mueller F, Nigg A et al. Relevance of grade 1 gray-scale ultrasound findings in wrists and small joints to the assessment of subclinical synovitis in rheumatoid arthritis. Arthritis Rheum 2013; 65: 1694-1701

15 Rees JD, Pilcher J, Heron C et al. A comparison of clinical vs. ultrasound determined synovitis in rheumatoid arthritis utilizing grayscale, power Doppler and the intravenous microbubble contrast agent 'Sono-Vue'. Rheumatology (Oxford) 2007; 46: 454-459

16 Naredo E, Bonilla G, Gamero F et al. Assessment of inflammatory activity in rheumatoid arthritis: a comparative study of clinical evaluation with grey scale and power Doppler ultrasonography. Ann Rheum Dis 2005; 64: 375-381

17 Baillet A, Gaujoux-Viala C, Mouterde G et al. Comparison of the efficacy of sonography, magnetic resonance imaging and conventional radiography for the detection of bone erosions in rheumatoid arthritis patients: a systematic review and meta-analysis. Rheumatology (Oxford) 2011; 50: 1137-1147

18 Rahmani M, Chegini H, Najafizadeh SR et al. Detection of bone erosion in early rheumatoid arthritis: ultrasonography and conventional radiography versus non-contrast magnetic resonance imaging. Clin Rheumatol 2010; 29: 883-891

19 Hammer HB, Bolton-King P, Bakkeheim $V$ et al. Examination of intra and interrater reliability with a new ultrasonographic reference atlas for scoring of synovitis in patients with rheumatoid arthritis. Ann Rheum Dis 2011; 70: 1995-1998

20 Naredo E, Moller I, Moragues C et al. Interobserver reliability in musculoskeletal ultrasonography: results from a "Teach the Teachers" rheumatologist course. Ann Rheum Dis 2006; 65: 14-19

21 Broll M, Albrecht K, Tarner I et al. Sensitivity and specificity of ultrasonography and low-field magnetic resonance imaging for diagnosing arthritis. Clin Exp Rheumatol 2012; 30: 543-547

22 Horikoshi M, Suzuki T, Sugihara M et al. Comparison of low-field dedicated extremity magnetic resonance imaging with articular ultrasonography in patients with rheumatoid arthritis. Mod Rheumatol 2010; 20: 556-560

23 Lassere $M$, McQueen $F$, Ostergaard $M$ et al. OMERACT Rheumatoid Arthritis Magnetic Resonance Imaging Studies. Exercise 3: an international multicenter reliability study using the RA-MRI Score. J Rheumatol 2003; 30: 1366-1375

24 Wohrle NK, Hellerhoff $K$, Notohamiprodjo $M$ et al. Automated breast volume scanner (ABVS): a new approach for breast imaging. Radiologe 2010; 50: 973-981

25 Wojcinski S, Farrokh A, Hille U et al. The Automated Breast Volume Scanner (ABVS): initial experiences in lesion detection compared with conventional handheld B-mode ultrasound: a pilot study of 50 cases. Int J Womens Health 2011; 3: 337-346 
26 Lin X, Wang J, Han F et al. Analysis of eighty-one cases with breast lesions using automated breast volume scanner and comparison with handheld ultrasound. Eur J Radiol 2012; 81: 873-878

27 Wang HY, Jiang YX, Zhu QL et al. Automated breast volume scanning: identifying 3-d coronal plane imaging features may help categorize complex cysts. Ultrasound Med Biol 2016; 42: 689-698

28 Xiao YM, Chen ZH, Zhou QC et al. The efficacy of automated breast volume scanning over conventional ultrasonography among patients with breast lesions. Int J Gynaecol Obstet 2015; 131: 293-296

29 Wang ZL, Xu JH, Li JL et al. Comparison of automated breast volume scanning to hand-held ultrasound and mammography. Radiol Med 2012; 117: 1287-1293

30 Zhang $\mathrm{Q}, \mathrm{Hu}$ B, Hu B et al. Detection of breast lesions using an automated breast volume scanner system. J Int Med Res 2012; 40: 300-306

31 Grunke M, Wendler J, Schuch F et al. Automated ultrasound for the detection of joint swelling in arthritic diseases. Ann Rheum Dis 2013; 72 (Suppl 3): 763

32 Kawashiri SY, Suzuki T, Nishino A et al. Automated Breast Volume Scanner, a new automated ultrasonic device, is useful to examine joint injuries in patients with rheumatoid arthritis. Mod Rheumatol 2015; 25: 837-841

33 Backhaus $M$, Ohrndorf S, Kellner $H$ et al. Evaluation of a novel 7-joint ultrasound score in daily rheumatologic practice: a pilot project. Arthritis Rheum 2009; 61: 1194-1201

34 Dougados M, Devauchelle-Pensec V, Ferlet JF et al. The ability of synovitis to predict structural damage in rheumatoid arthritis: a comparative study between clinical examination and ultrasound. Ann Rheum Dis 2013; 72: 665-671

35 Naredo E, D'Agostino MA, Wakefield RJ et al. Reliability of a consensusbased ultrasound score for tenosynovitis in rheumatoid arthritis. Ann Rheum Dis 2013; 72: 1328-1334

36 Wakefield RJ, Gibbon WW, Conaghan PG et al. The value of sonography in the detection of bone erosions in patients with rheumatoid arthritis: a comparison with conventional radiography. Arthritis Rheum 2000; 43: 2762-2770

37 Ohrndorf S, Fischer IU, Kellner $H$ et al. Reliability of the novel 7-joint ultrasound score: results from an inter- and intraobserver study performed by rheumatologists. Arthritis Care Res (Hoboken) 2012; 64: 1238-1243

38 Chavez-Lopez MA, Hernandez-Diaz C, Moya C et al. Inter- and intraobserver agreement of high-resolution ultrasonography and power Doppler in assessment of joint inflammation and bone erosions in patients with rheumatoid arthritis. Rheumatol Int 2013; 33: 173-177
39 Vlad V, Berghea F, Libianu $S$ et al. Ultrasound in rheumatoid arthritis: volar versus dorsal synovitis evaluation and scoring. BMC Musculoskelet Disord 2011; 12: 124

40 Witt MN, Mueller F, Weinert $P$ et al. Ultrasound of synovitis in rheumatoid arthritis: advantages of the dorsal over the palmar approach to finger joints. J Rheumatol 2014; 41: 422-428

41 Kawashiri SY, Suzuki T, Nakashima Y et al. Ultrasonographic examination of rheumatoid arthritis patients who are free of physical synovitis: power Doppler subclinical synovitis is associated with bone erosion. Rheumatology (Oxford) 2014; 53: 562-569

42 Foltz V, Gandjbakhch F, Etchepare F et al. Power Doppler ultrasound, but not low-field magnetic resonance imaging, predicts relapse and radiographic disease progression in rheumatoid arthritis patients with low levels of disease activity. Arthritis Rheum 2012; 64: 67-76

43 Scire CA, Montecucco C, Codullo V et al. Ultrasonographic evaluation of joint involvement in early rheumatoid arthritis in clinical remission: power Doppler signal predicts short-term relapse. Rheumatology (Oxford) 2009; 48: 1092-1097

44 Dougados M, Jousse-Joulin S, Mistretta F et al. Evaluation of several ultrasonography scoring systems for synovitis and comparison to clinical examination: results from a prospective multicentre study of rheumatoid arthritis. Ann Rheum Dis 2010; 69: 828-833

45 Naredo E, Rodriguez M, Campos C et al. Validity, reproducibility, and responsiveness of a twelve-joint simplified power doppler ultrasonographic assessment of joint inflammation in rheumatoid arthritis. Arthritis Rheum 2008; 59: 515-522

46 Hammer HB, Kvien TK. Comparisons of 7- to 78-joint ultrasonography scores: all different joint combinations show equal response to adalimumab treatment in patients with rheumatoid arthritis. Arthritis Res Ther 2011; 13: R78

47 Werner SG, Langer HE, Schott $P$ et al. Indocyanine green-enhanced fluorescence optical imaging in patients with early and very early arthritis: a comparative study with magnetic resonance imaging. Arthritis Rheum 2013; 65: 3036-3044

48 van Onna M, Ten Cate DF, Tsoi KL et al. Assessment of disease activity in patients with rheumatoid arthritis using optical spectral transmission measurements, a non-invasive imaging technique. Ann Rheum Dis 2016; 75: 511-518 